\title{
Pancreatic Function in the Reserpinized Rabbit- a Model for Cystic Fibrosis. I. Effect of Secretin
}

\author{
MITCHELL L. SHIFFMAN, ${ }^{(24)}$ MARY J. GILLON AND WILLIAM R. GALEY ${ }^{(26)}$ \\ Department of Physiology, University of New Mexico School of Medicine, Albuquerque, NM, USA
}

\begin{abstract}
Summary
Pancreatic juice was collected from rabbits treated with reserpine and from untreated controls. The volume of pancreatic juice secreted, flow rate and the bicarbonate output were all significantly reduced in the treated animals during both spontaneous flow and during secretin-stimulated flow. On the other hand, the total protein concentration, the amylase activity and the calcium concentration of the pancreatic juice were all significantly elevated in the treated animals. The elevation in the total protein concentration appeared to be due to both increased amounts of protein and decreased amounts of water. Of particular interest was that secretin stimulation caused the same \% increase in the flow rate and output of pancreatic juice in both control and reserpine treated rabbits. The method by which fluid is secreted by the treated animal, therefore, appeared to be depressed at all times and under all conditions. Decreased volumes of pancreatic juice, a decreased bicarbonate output and increased concentrations of protein and calcium are found in this model and are consistent with clinical findings present in the pancreatic secretions obtained from individuals with cystic fibrosis. Therefore, the similarities between secretions of the reserpine treated rabbit and those observed in the cystic fibrosis patient support its use as an experimental model for investigating the abnormal pancreatic secretions in this disease.
\end{abstract}

\section{Speculation}

Rabbits treated with reserpine for 7 days secrete smaller volumes of pancreatic juice at lower rates of flow during both spontaneous and secretin-stimulated conditions. This juice contains elevated levels of total protein, enzymes, calcium and smaller amounts of bicarbonate. Because these alterations are common in patients with $\mathrm{CF}$, the reserpine-treated rabbit appears to be a good model to investigate the perturbations taking place in the pancreas during the course of this disease.

The study of cystic fibrosis (CF) has been hampered by the lack of an equivalent disease in a lower species. For this reason attempts have been made to pharmacologically perturb the exocrine secretions of an experimental animal to the point where they resemble what is seen in this disease $(8,10)$. One such model is the chronically reserpinized rat. Rats treated for several days with reserpine develop morphologic and secretory changes in the submaxillary gland $(9,11)$ and in the pancreas $(6,16)$ which resemble those present in CF patients. The $\mathrm{Na}^{+}$transport inhibitory factor, present in the saliva of CF patients (7) has been demonstrated in the saliva of reserpinized rats as well (13). In addition, this treatment increases the pulmonary secretion of phospholipids (14), total protein (21) and of a specific type of glycoprotein which is also present in lung lavages of CF patients (21). These alterations seem to indicate that reserpinization creates a generalized exocrine gland dysfunction resulting in a fairly complete animal model with which this disease can be studied.

Although the pancreas is one of several secretory organs affected by $C F$, pancreatic secretions have not been as extensively studied in CF patients as have other of the more easily accessible exocrine gland products. Therefore, the chronically reserpinized animal provides an avenue by which this secretion can be extensively studied. Rabbits are a particularly good species with which to study pancreatic secretion because of their diffuse pancreatic structure, easily accessible ductal system and their high rate of spontaneous secretion. We have, therefore, attempted to create an animal model of $\mathrm{CF}$ in rabbits by treating these animals with reserpine. This study compares the composition and the volume of the pancreatic juice during both spontaneous secretion and during stimulation with secretin in rabbits treated for 7 days with reserpine and in untreated controls.

\section{MATERIALS AND METHODS}

Male New Zealand White rabbits weighing from 1.5 to $3.0 \mathrm{~kg}$ were used throughout this study. Both control rabbits and those selected to undergo reserpine treatment were housed in the same quarters and allowed free access to the same standard diet and water. Twenty-four $h$ before the start of the experiment each animal was deprived of food but not water. Those animals selected to undergo reserpine treatment received seven daily intramuscular injections of reserpine (Ciba Pharmaceutical Co., Summit, NJ) at a dose of $0.5 \mathrm{mg} / \mathrm{kg}$ of body weight.

On the day of the experiment, the rabbit was anesthetized with an intravenous injection of dial-urethane (Ciba Pharmaceutical Co., Summit, NJ) at a dose of $1 \mathrm{ml} / \mathrm{kg}$ of body weight. The animal was placed on a heated animal board in a supine position and a tracheostomy performed by inserting a piece of PE-360 tubing into the trachea. The femoral artery was then cannulated with PE60 tubing and connected to a Beckman dynograph via a pressure transducer. This allowed for the continuous monitoring of arterial blood pressure and pulse rate during the course of the experiment and for the removal of arterial blood samples for the determination of blood $\mathrm{pH}$. Blood $\mathrm{pH}$ was monitored at various times during the experiment utilizing a Radiometer PHM 27 (Radiometer, Copenhagen, Denmark) with a micro $\mathrm{pH}$ electrode attachment. The femoral vein was cannulated with PE-50 tubing and used for the infusion of the hormone secretin. Subsequent to these surgical procedures the animal was placed on its side and supplemented with oxygen at a flow rate of 1.5 liters/min via a t-tube attachment to the trachea. An incision was made in the right side of the animal's abdomen exposing the first duodenal loop, which wraps around the pancreas and contains the site of attachment of the main pancreatic duct, completely separate from the bile duct. The pancreas was lifted out of the abdominal cavity. A piece of PE-10 tubing was inserted into the main pancreatic duct at a distance of not more than $3 \mathrm{~mm}$ from the sphincter of Oddi and tied in place with silk suture. The pancreas was then carefully replaced into the body cavity with the main duct cannula brought through the incision. This was then closed with wound clips around the cannula to prevent the loss of body heat, which was monitored via a rectal thermister and a YSI Model 43 telethermometer (Yellow Springs Instrument Co., Yellow Springs, $\mathrm{OH}$ ). 
Immediately upon cannulation of the main pancreatic duct, the flow of pancreatic juice began. The juice was collected under water-equilibrated paraffin oil in tared tubes. Juice was collected immediately after cannulation at timed intervals. At the end of each collection period, the tubes were reweighed to obtain a gravimetric determination of the amount of juice produced. The samples were then refrigerated until enzyme assays, to be described below, could be performed. Pancreatic juice was collected under free flow conditions for $1 \mathrm{~h}$ before stimulation with secretin. Pure natural secretin was purchased from the Gastrointestinal Hormone Laboratory of the Karolinska Institute, Stockholm, Sweden. Each vial contains 75 clinical units of the purified hormone and is said to be free of cholecystokinin (CCK) contamination. This preparation was dissolved in saline and infused at a rate of $1 \mathrm{unit} / \mathrm{kg}$ of body weight per min with a Sage infusion pump Model 355 (Sage Instrument Co., Cambridge, MA) for a period of $15 \mathrm{~min}$. Pancreatic juice was collected during and after secretin stimulation for a total of $1 \mathrm{~h}$ in the same manner that was used for the collection of the spontaneously flowing juice.

The bicarbonate concentration in each sample of the pancreatic juice was measured immediately after its collection. The waterequilibrated paraffin oil was removed from above the pancreatic juice and $100 \mu \mathrm{l}$ of sample was immediately injected into the common chamber of a Radiometer BMS 3 MK 2 micro blood gas system with a PHM 72 MK 2 digital acid base analyzer attachment (Radiometer, Copenhagen, Denmark). The $\mathrm{PCO}_{2}$ and $\mathrm{pH}$ of the sample was then measured and the bicarbonate concentration calculated by the Henderson-Hasselbalch equation.

The amylase activity of each sample was determined utilizing the Harleco Amylase Assay \#64191 (Harleco Co., Gibbstown, NJ) with a slight modification in the procedure. Two and onehalf $\mathrm{ml}$ of starch reagent was pipetted into a $25 \mathrm{ml}$ volumetric flask and warmed at $37^{\circ} \mathrm{C}$ for $5 \mathrm{~min}$. Fifty $\mathrm{ml}$ of sample, which was previously diluted from 1000-5000 times with distilled water, was then added. This mixture was incubated for exactly $7.5 \mathrm{~min}$ at which time $2.5 \mathrm{ml}$ of iodine reagent was added to terminate the reaction. This mixture was then brought up to $25 \mathrm{ml}$ with distilled water and its optical density read immediately at $660 \mathrm{~nm}$ in a Coleman Junior spectrophotometer Model 6A (Coleman Instrument Co., Maywood, IL).

Total protein was measured by the Bio-Rad total protein assay (Bio-Rad Laboratories, Richmond, CA) at $595 \mathrm{~nm}$ utilizing a Coleman Junior spectrophotometer Model 6A. The concentration of protein in each sample of pancreatic juice was then determined from a previously measured standard curve.

The calcium content of each sample of pancreatic juice was measured with an IL Flame Atomic Absorption Spectrophotometer (Instrumentation Laboratories, Willmington, MA). Thirty $\mathrm{ml}$ of sample was added to $2 \mathrm{ml}$ of double distilled water to provide enough fluid for the determination. A $1 \mathrm{mg} / \mathrm{ml} \mathrm{CaCl}{ }_{2}$ solution served as the standard.

A Students $t$ test was used to determine if the difference between any 2 sample means was significant. $P \leq 0.05$ was considered to be significant.

\section{RESULTS}

\section{FLOW RATES AND OUTPUTS OF PANCREATIC JUICE}

The flow rate and the output of pancreatic juice obtained from control rabbits and from those rabbits treated for 7 days with reserpine are presented in Table 1 . This table indicates that those rabbits treated with reserpine produced significantly $(P<0.025)$ smaller amounts of spontaneously flowing pancreatic juice during the $1 \mathrm{~h}$ collection period and demonstrated significantly smaller flow rates $(P<0.025)$ under these free flow conditions when compared with untreated controls.

The effect of pure natural secretin upon the flow rate of both control and treated rabbits is illustrated in Figure 1. Upon the administration of secretin, the pancreatic juice flow rates of both control and treated animals were observed to increase to a peak value. As can be seen from this figure, both control and treated animals reached their maximum flow rate at approximately the same time after the start of the secretin infusion. Upon termination of the infusion both normal and treated animals demonstrated a gradual fall in their flow rates back toward their respective basal levels. The time period for this response appeared to be approximately the same for the two groups of animals. Figure 1 also demonstrates that the flow rates attained by the control group were consistently higher than those observed for reserpinized rabbits throughout the experiment.

Secretin stimulation caused both the flow rate and the output of the pancreatic juice to approximately double over those values obtained during the spontaneous flow condition. This effect was observed in both control and reserpine treated rabbits (Table 1). Table 1 also illustrates that during secretin stimulation the control animals still produce significantly $(P<0.025)$ greater amounts of pancreatic juice during the $1 \mathrm{~h}$ following the initiation of the secretin infusion and still attained significantly greater flow rates $(P<0.010)$ when compared with the reserpinized rabbits.

\section{PROTEIN AND AMYLASE}

During spontaneous flow, the pancreatic juice of treated animals contained nearly 3 times the amylase activity (concentration) and an equally elevated protein concentration when compared with untreated controls (Fig. 2). It can also be seen from this figure that upon secretin stimulation there was a decrease in both the protein concentration and the amylase activity of the pancreatic juice. This decrease was observed for both control and reserpine

Table 1. Output and flow rate of pancreatic juice from control and treated animals ${ }^{1}$

\begin{tabular}{lcc}
\hline & Control & Treated \\
\hline Spontaneous flow & & \\
Juice output $^{2}(\mathrm{~g})$ & $0.87 \pm 0.05(15)^{4}$ & $0.66 \pm 0.08(12)$ \\
Flow rate $^{3}$ & $38.7 \pm 4.5(9)$ & $25.3 \pm 4.0(7)$ \\
Secretin-stimulated flow $^{\text {Juice output }}{ }^{2}$ (g) & $1.77 \pm 0.19(11)$ & $1.27 \pm 0.11(13)$ \\
Flow rate $^{3}$ & $75.2 \pm 7.7(9)$ & $50.3 \pm 3.8(8)$ \\
Maximum flow rate $^{3}$ & $80.1 \pm 8.3(9)$ & $61.5 \pm 3.8(8)$ \\
\hline
\end{tabular}

' Values are given as \pm S.E.

${ }^{2}$ Juice output represents the amount of juice secreted during the $1 \mathrm{~h}$ collection periods.

${ }^{3}$ Flow rate expressed as $\mathrm{mg}$ of juice/min/g of fate free dry panc:eatic weight.

${ }^{4}$ Number in parenthesis indicates number of animals studied

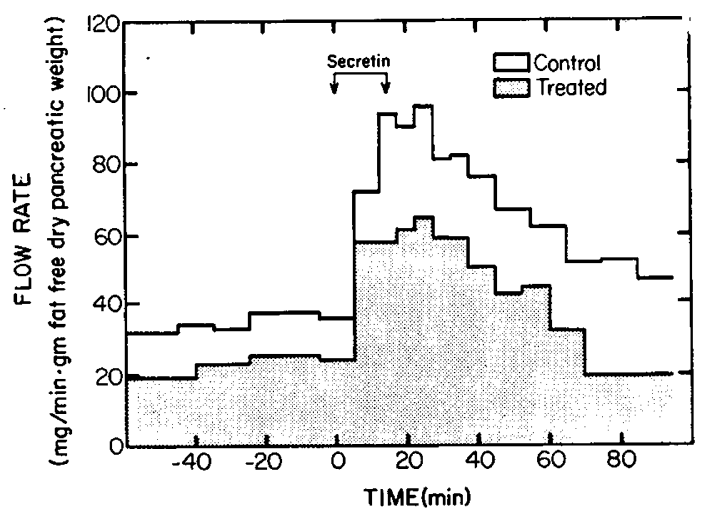

Fig. 1. Pancreatic response to secretin stimulation during the cuurse of the experiment. Secretin was administered at time, $t=0$, for a period of 15 min. Samples were collected at timed intervals for 5, 10 or 15 min. depending upon the flow rate. The flow rates given for each time interval represents the average values obtained for each group of animals at that time of the experiment. The number of animals used in the study are as follows: control (13); treated (10). 
treated animals. In control animals, both of these parameters decreased approximately $66 \%$. On the other hand, in treated animals, $67 \%$ and $76 \%$ decreases were observed in the amylase activity and the protein concentration respectfully. Therefore, during this period of secretin stimulation, the amylase activity of the pancreatic juice of treated animals was still observed to be nearly 3 times as great as in the juice obtained from the untreated controls. However, the protein concentration of the pancreatic juice obtained from the treated group was only twice as great as that determined for the control group during this period.

The secretion of total protein is further illustrated in Figure 3. This figure demonstrates that the total protein concentration is always higher in the juice produced by the reserpinized rabbits at the varying flow rates attained during the course of the experiment. Similar observations were made for the amylase concentration and the calcium concentration (see below).

The output of amylase and protein, that is, the amount of amylase and protein removed from the pancreatic ductal system during the $1 \mathrm{~h}$ collection periods is illustrated in Figure 4. This figure demonstrates that during the spontaneous flow of pancreatic

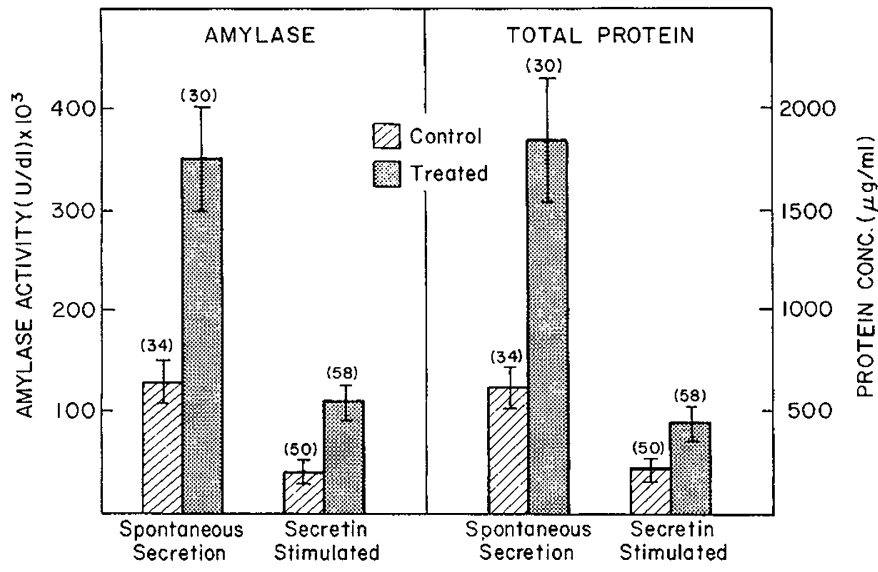

Fig. 2. Amylase activity (concentration) and total protein concentration in the pancreatic juice of control and treated animals under various conditions. Values are given as \pm S.E. and are representative of the entire collection period indicated. Number in parenthesis indicates the total number of sample determinations. The number of animals used in the study are as follows: control (9); treated (9).

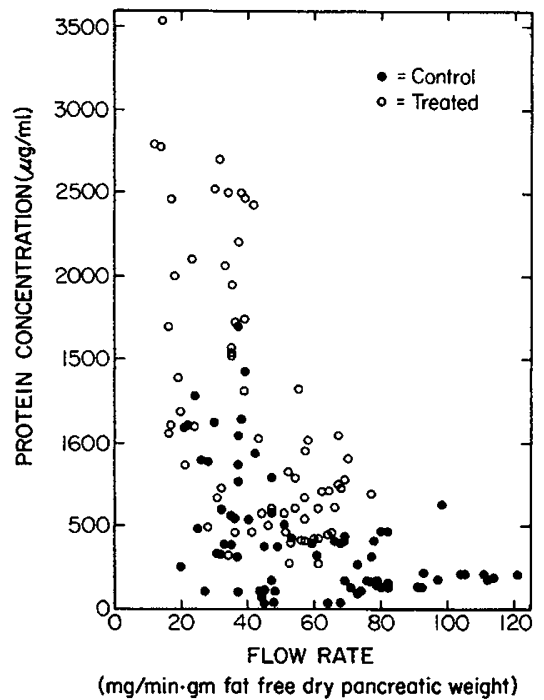

Fig. 3. Protein concentration of the pancreatic juice as a function of the juice flow rates attained during the course of the experiment for both control and treated animals. Each point is representative of a single pancreatic juice sample. The number of animals used in the study are as follows: control (9); treated (9). juice there was twice as much amylase and protein output by the pancreas in treated animals as was produced by the control animals. Upon secretin stimulation there was a decrease in the output of both of these parameters. In control animals both the output of amylase and the output of total protein were observed to decrease approximately $45 \%$. In treated animals the decreases were $42 \%$ and $52 \%$ respectfully. During this period of secretin stimulation, amylase outputs from reserpinized rabbits were still found to be slightly more than twice as great as those obtained from untreated controls. However, the protein output in the treated animals was only 1.8 times as great as that observed in the pancreatic juice of the control group.

This decrease in the protein output during secretin stimulation is further illustrated in Figure 5. As can be seen, the protein output from both control and treated animals started at a high level upon cannulation of the main pancreatic duct and gradually fell during the first $h$ of the experiment. At this point, secretin was administered. Upon the administration of secretin, control rabbits at first responded with an immediate, short increase in the protein output followed by a gradual decrease during the next $h$ of the experiment. This relationship may be taken to indicate that protein is washed free from the pancreatic ductal system. This same type of relationship has been observed previously in humans undergoing CCK-secretin pancreatic function tests $(1,4,20)$. This relationship, however, was not observed in the treated animals. Upon secretin stimulation all that was found was a rapid fall in the protein output.

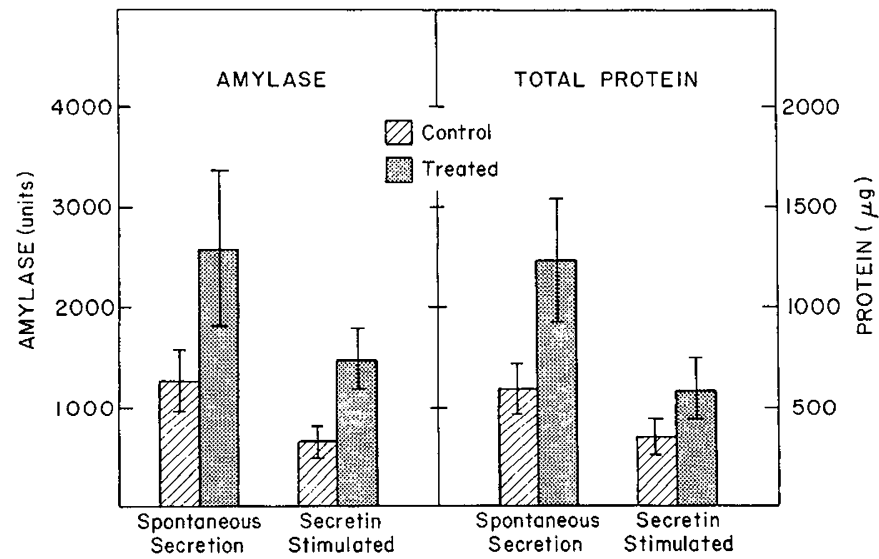

Fig. 4. Amylase and total protein output from control and treated animals under various conditions. Values are given as \pm S.E. and represent the total output during the $1 \mathrm{~h}$ collection period indicated. The number of animals used in the study are as follows: control (9); treated (9).

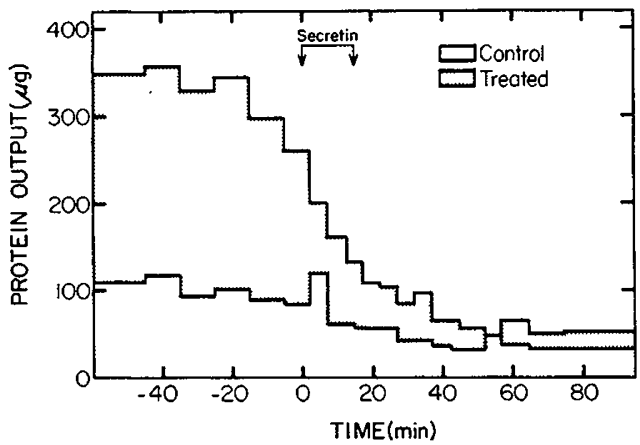

Fig. 5. Protein output in the pancreatic juice during the course of the experiment. Secretin was administered at time, $t=0$, for a period of 15 min. Samples were collected at $10 \mathrm{~min}$. intervals during the period of spontaneous secretion and at $5 \mathrm{~min}$. intervals once the secretin infusion had started. The output given for each time interval represents the average values obtained for each group of animals at that time of the experiment. The number of animals used in the study are as follows: control (9); treated (9). 
The amylase specific activity, the proportion of total protein removed from the pancreatic ductal system that is amylase, is presented in Table 2 . This table indicates that for control animals this ratio was unaltered by secretin stimulation. In treated animals, during the spontaneous flow of pancreatic juice, this ratio was not altered from that obtained for the untreated controls. However, during secretin stimulation of the reserpinized animals this ratio did increase significantly $(P<0.005)$, indicating that relatively more amylase appeared in the final pancreatic juice with respect to other types of proteins present.

\section{BICARBONATE}

The bicarbonate output of the pancreatic juice during the $1 \mathrm{~h}$ collection periods from both control and treated animals is presented in Table 3. This data indicates that during the time of spontaneous flow the total output of bicarbonate in the pancreatic juice in the reserpinized rabbits was significantly less $(P<0.05)$ than that observed in the control animals. Secretin stimulation caused an increase in the bicarbonate output in both control and treated rabbits. However, the output of this anion remained significantly greater $(P<0.05)$ in the control group (Table 3$)$.

\section{CALCIUM}

During unstimulated conditions, the pancreatic juice collected from reserpinized rabbits contained an average calcium concentration that was significantly greater $(P<0.001)$ than the juice collected from the untreated controls (Table 3). During secretin stimulated flow conditions, the calcium concentration in the pancreatic juice of both control and treated animals decreased from their respective free flow values. The concentration of this divalent cation, however, was always greater in the reserpinized rabbits at

Table 2. Amylase specific activity in control and treated animals ${ }^{1}$

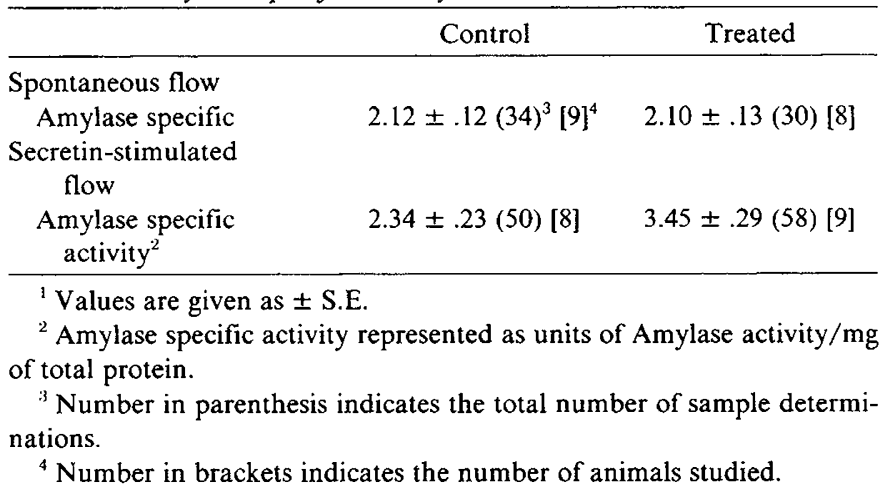

Table 3. Bicarbonate output and calcium concentration of the pancreatic juice from control and treated animals ${ }^{1}$

\begin{tabular}{lcc}
\hline \multicolumn{2}{c}{ Control } & Treated \\
\hline $\begin{array}{l}\text { Spontaneous flow } \\
\text { Bicarbonate output }{ }^{2} \\
\quad(\mu \mathrm{eq})\end{array}$ & $45.4 \pm 7.0[7]^{4}$ & $29.0 \pm 5.7(7)[7]$ \\
$\begin{array}{c}\text { Calcium concentration } \\
(\mathrm{mg} / \mathrm{ml})\end{array}$ & $18.0 \pm 1.5(21)^{3}[6]$ & $56.8 \pm 4.9(13)[5]$ \\
$\begin{array}{c}\text { Secretin-stimulated } \\
\quad \text { flow } \\
\text { Bicarbonate output } \\
\quad\end{array}$ & $116.6 \pm 15.1[6]$ & $78.8 \pm 7.3[5]$ \\
$\quad(\mu$ eq) \\
$\begin{array}{c}\text { Calcium concentration } \\
(\mathrm{mg} / \mathrm{ml})\end{array}$ & $11.9 \pm 1.5(30)[6]$ & $22.9 \pm 2.7(30)[5]$ \\
\hline
\end{tabular}

\footnotetext{
' Values are given as \pm S.E.

${ }^{2}$ Bicarbonate output represents the total amount of bicarbonate secreted during the $1 \mathrm{~h}$ collection periods.

${ }^{3}$ Numbers in parenthesis indicates the total number of sample determinations.

${ }^{4}$ Numbers in brackets indicates the number of animals studied.
}

all rates of pancreatic juice flow. As a result, the average calcium concentration during the course of secretin stimulation was found to be significantly $(P<0.001)$ elevated in the juice of the treated animals (Table 3 ).

\section{DISCUSSION}

The results of the present study confirm previous observations made upon the pancreas of the reserpinized rat. In these earlier studies altered secretory responses to CCK, secretin (16) and to other neurohormonal agents which elicit pancreatic function (15) were observed. Upon stimulation with CCK these investigators noted increases in both the concentration and the output of amylase and total protein in the pancreatic juice of fasted reserpine treated rats. Smaller flow rates, decreases in the bicarbonate output and alterations in the normal pattern of bicarbonate secretion were also observed in these animals upon secretin stimulation. Similar increases in both the amylase and the protein concentrations and amylase and protein outputs of the pancreatic juice were observed in reserpinized rabbits during both secretin stimulated and unstimulated conditions during the course of this study (Fig. 2,3 , and 4). This study also demonstrated that 7 days of reserpine treatment resulted in decreases in the output of pancreatic juice and in the flow rate of this juice during spontaneous secretion as well as decreases in the juice output, in the average flow rate and in the maximum flow rate attained during secretin stimulation (Table 1). These observations not only confirm those of other investigators but demonstrate that these reserpine-induced alterations can be observed in animals other than the rat. This indicates that the action of reserpine must be a generalized effect on the cellular physiology of exocrine glands and is not a species specific phenomenon.

Pancreatic secretions have not been extensively studied in CF patients. In those studies which have been performed, the most important alterations that were noticed involved large decreases in the total amount of pancreatic juice produced. In general, CF patients produce only $20 \%$ of the pancreatic juice secreted by normal individuals in response to secretin stimulation $(3,23)$. Decreases in the bicarbonate output and increases in the concentration of proteins were also noted in these ir dividuals (3). It is therefore interesting to point out that the perilrbations in pancreatic secretion of the experimental animal induced by reserpine treatment also involve decreases in the amount of pancreatic juice produced and decreases in the bicarbonate ortput. Increases in the concentration of the organic fraction of this secretion are observed subsequent 7 days of reserpine treatment as well. However, the effect of reserpine treatment on the output of the pancreatic juice does not appear to be as dramatic as the CF condition. For example, in reserpinized rats a $35 \%$ decrease in the p increatic juice was observed when treated animals were compa $a_{1}$ ed with untreated controls during secretin stimulation (16). In these studies on reserpinized rabbits, only a $25 \%$ decrease in the output of the pancreatic juice during secretin stimulation was observed (Table 1). It must be noted, however, that these effects were observed after only 7 days of treatment.

Pancreatic juice is thought to be a mixture of two components controlled by two different hormones. A scanty, highly concentrated enzyme solution is released by the acinar cells in response to $\mathrm{CCK}$. On the other hand, secretin causes the production of a much larger water and electrolyte component secreted by the centroacinar and ductal cells $(17,18)$.

The abnormal pattern of pancreatic secretion observed in $\mathrm{CF}$ patients was explained by Hadorn, et. al. (3) by assuming that the water and electrolyte fraction of the pancreatic juice was reduced. According to this assumption, the abnormally high enzyme concentrations in the juice were due to a reduced dilution of this organic fraction. It was also thought that these reduced volumes of water may not have been adequate to "wash" this viscous, concentrated proteinaceous material from the pancreatic ductal system. This could lead to mechanical obstruction and distention of the ductal system and eventually to the impairment of flow. An 
overproduction of the organic fraction was also proposed by this group of investigators as an alternative explanation for the reduced secretory volumes present in the pancreatic secretion of CF patients (5). Both mechanisms appear to be operating in the pancreas in the reserpinized animal.

The pancreatic juice of the reserpinized rabbits used in this study appeared to contain both a decreased water content and an increased organic fraction. The decreased volumes of water of this secretion can be observed directly in Table 1 and indirectly by comparing Figure 2 and 4 . Figure 2 indicates that the protein and amylase concentrations in the pancreatic juice of the treated animals were observed to be 3 times that seen in the controls during spontaneous secretion. However, the output of amylase and protein in the treated animals was only observed to be twice that seen in the controls under these same conditions (Figure 4). This indicates that there is less water present with the result being to elevate the protein and amylase concentrations over the outputs. In addition, histologic studies upon the reserpinized rabbit reveal a pancreatic ductal system containing numerous intraductal precipitates (19). In CF patients this inspissated material is usually described as "mucoid masses" on the basis of histologic criteria (2). In both reserpinized rats (6) and reserpinized rabbits (19) these ductal precipitates also appear to be mucoid in nature as indicated by their ability to stain PAS-positive.

Although the pancreas of treated animals produces smaller amounts of water and electrolytes than does the pancreas of the control animals, its response to secretin does not appear to be altered. This is demonstrated in Figure 1, which indicates that the pancreas of the treated animal responded with the same time course to the administration of secretin as did the pancreas of the control animals. Also, Table 1 illustrates that in both control and treated rabbits secretin stimulation resulted in a near doubling of the flow rate. This indicates that the general mechanism that regulates fluid secretion and affects the pancreas of treated animals is suppressed at all times and under all conditions. The result is that the flow rates of pancreatic juice attained by the treated rabbits were always significantly depressed when compared with the pancreatic juice flow rates of the untreated controls. This observation is in direct conflict with that of Hadorn, et al. $(3,5)$ who observed practically no increase in the basal level of water and electrolyte secretion by the pancreas of a CF patient in response to secretin stimulation.

These observations on the reserpine-treated rabbit indicate that its pancreatic secretory functions are altered to the point where they resemble those present in the pancreas of CF patients. Furthermore, these alterations are in agreement with the more extensive studies of other investigators on reserpinized rats. These investigators have demonstrated that the salivary glands $(9,10$, $12)$, lungs $(21,14)$ and pancreas $(16,15)$ as well as the secretions from these glands are altered by reserpine treatment to resemble those seen in CF patients as well. The mechanism by which reserpine alters the normal physiology of the pancreas to produce these perturbations is not yet known. At the present time it is believed that reserpine provides a direct toxic action on the cell involving changes in membrane permeability and calcium homeostasis (22). Calcium is required for the normal stimulus-secretion coupling mechanism of the pancreatic acinar cells. An alteration in this area has previously been proposed as the basic defect in CF patients (2).

Although it is obvious that these experimental rabbits do not have $C F$, it does appear that many of their pancreatic exocrine products are modified to the extent where they resemble what is seen clinically in this disease. The mechanism by which reserpine alters these secretions when elucidated may or may not be similar to the genetic alterations produced by CF. Nevertheless, the fact that this experimental animal has been shown to resemble the exocrine secretions of the CF patient, warrants its use to answer many of the unanswered questions concerning this disease.

\section{REFERENCES AND NOTES}

1. Burton, P., Evans, D. G., Harper, A. A., Howat, H. T., Oleesky, S., Scott, J. E., and Varley, $\mathrm{H}$ : : A test of pancreatic function in man based on the analysis of duodenal contents after administration of secretin and pancreozymin. Gut, 1 : $111(1960)$.

2. Di Sant'Agnese, P. A. and Talamo, R. C.: Pathogenesis and pathophysiology of cystic fibrosis of the pancreas. New Eng. J. Med., 277: 1287 (1967).

3. Hadorn, B., Johansen, P. G. and Anderson, C. M.: Pancreaozymin secretin test of exocrine pancreatic function in cystic fibrosis and the significance of the result for the pathogenesis of the disease. Can. Med. Assoc. J. 98: 377 (1968).

4. Hadorn, B., Zoppi, G., Shmerling, D. H., Prader, A., McIntyre, I. and Anderson, C. H.: Quantitative assessment of exocrine pancreatic function in infants and children. J. Pediatr., 73: 39 (1968).

5. Hadorn, B., Johansen, P. G. and Anderson, C. H.: Exocrine pancreatic function in cystic fibrosis. In: Proc. Fifth Int. Cystic Fibrosis Conference. D. Lawson, Ed. pp. 55-65. Churchill College, Cambridge. (1969).

6. Immken, L., Martinez, J. R., Hess, R. A. and Barbero, G. J.: The chronically reserpinized rat as a possible model for cystic fibrosis. Ill. Histochemistry of exocrine glands. Cystic Fibrosis Club Abstracts, XVI Annual Meeting 9-1975.

7. Mangos, J. A. and McSherry, N. R.: Sodium transport: Inhibitory factor in sweat of patients with cystic fibrosis. Science, 158: 135 (1967).

8. Mangos, J. A., McSherry, N. R., Benke, P. J. and Spock, A.: Studies on the pathogenesis of cystic fibrosis: The isoproterenol treated rat as an experimental model. In Fifth International Cystic Fibrosis Conference, pp 25-34. (Churchill College, Cambridge, 1969).

9. Martinez, J. R., Adelstein, E., Quissel, D. and Barbero, G. J.: The chronically reserpinized rat as a possible model for cystic fibrosis. I. Submaxillary gland morphology and ultrastructure. Pediatr. Res.. 9: 463 (1975).

10. Martinez, J. R., Adshead, P. C., Quissel, D. O. and Barbero, G. J.: The chronically reserpinized rat as a possible model for cystic fibrosis. II Composition and cilioinhibitory effects of submaxillary saliva. Pediatr. Res., 9: 470 (1975).

11. Martinez, J, R., Quissel, D. O., Wood, D. L., and Giles, M.: Abnormal secretory response to parasympathommetric and sympathommetric stimulation from the submaxillary gland of rats treated with reserpine. J. Pharmacol. Exp. Ther., 194: 384 (1975).

12. Martinez, J. R., Martinez, A. M., Garret, L. and Korman, P.: The chronically reserpinized rat as a model for cystic fibrosis: $\mathrm{Na}^{+}$transport inhibitory effects in submaxillary saliva. Pediatr. Res., (in press), (1979).

13. Martinez, J. R., Braddock, M. E., Martinez, A. M. and Cooper, C.: Effect of chronic reserpine administration of $\mathrm{K}^{+}$and amylase release from the rat parotid gland. Pediatr. Res., (in press), (1979).

14. Miwhinney, L. P., Feather, M. S., Martinez, J. R. and Barbero, G. J.: The chronically reserpinized rat as an animal model for cystic fibrosis: I. Acute effect of isoproterenol and pilocarpine upon pulmonary lavage fluid. Pediatr. Res., (in press), (1979).

15. Morton, D., Parker, A. Estrada, P. and Martinez, J. R.: Exocrine pancreatic secretion in rats treated with reserpine following stimulation with pilocarpine, dopamine and ceurulin. Pediatr.. Res., (in press), (1979).

16. Perlmutter, J. and Martinez, J. R.: The chronically reserpinized rat as a possible model for cystic fibrosis. VII. Alterations in the secretory response to cholecystokinin and to secetin from the pancreas in vivo. Pediatr. Res., 12: 188 (1978).

17. Sewell, W. A. and Young, J. A.: Secretion of electrolytes by the pancreas of the anesthetized rat. J. Physiol., 252: 379 (1975).

18. Shaw, A. M. and Heath, T.: The phases of pancreatic secretion in rats. Quart. J, Exp. Physiol., 58: 229 (1973).

19. Shiffman, M. L., Gillon, M. J., and Galey, W. R.: Water and electrolyte secretion by the pancreas of the reserpinized rabbit: a model for Cystic Fibrosis in Perspective in Cystic Fibrosis, Ed: J. M. Sturges. Canadian Cystic Fibrosis Foundation, Toronto. 1: 92-96 (1980).

20. Sun. D. C. H., and Shay, H.: Pancreozymin-secretin test. The combined study of serum enzymes and duodenal contents in the diagnosis of pancreatic disease. Gastroent., 38: 570 (1960)

21. Thompson, F. E., Quissel, D. O., Williams, C. H. and Martinez, J. R.: The chronically reserpinized rat as a possible model for cystic fibrosis. IV. The protein composition of pulmonary lavage fluid. Pediatr. Res., 10: 632 (1976).

22. Wood, D. L. and Martinez, J. R.: The chronically reserpinized rat as a possible model for cystic fibrosis. VI. Synergistic effects of isoproterenol on $\mathrm{Ca}^{++}$and protein in the submaxillary gland Pediatr., Res., 11: 827 (1977).

23. Zoppi, G.. Shmerling, D. H., Gaburro, D. and Prader, A.: The electrolyte and protein contents and outputs in duodenal juice after pancreaozymin and secretin stimulation in normal children and in patients with cystic fibrosis. Acta Paediat. Scand., 59: 692 (1970).

24. Present Address: Robert C. Schwartz Cystic Fibrosis Center, State University of New York, Upstate Medical Center, Department of Pediatrics, Syracuse, New York.

25. The authors would like to acknowledge the assistance of Mrs. Tillie Lucero for her work on this manuscript. This work was supported in part by a grant from the NIH. Grant 2R01 AM17843.

26. Requests for reprints should be addressed to: Dr. William R. Galey, Department of Physiology, University of New Mexico, School of Medicine, Alburquerque, New Mexico, 87131.

27. Received for publication December 17, 1980.

28. Accepted for publication June 17, 1981. 